University of Vermont

UVM ScholarWorks

$1-1-2015$

\title{
Characterization of increased persistence and intensity of precipitation in the northeastern United States
}

\author{
Justin Guilbert \\ University of Vermont \\ Alan K. Betts \\ Donna M. Rizzo \\ Univeristy of Vermont \\ Brian Beckage \\ University of Vermont \\ Arne Bomblies \\ University of Vermont
}

Follow this and additional works at: https://scholarworks.uvm.edu/cemsfac

Part of the Climate Commons

\section{Recommended Citation}

Guilbert, J., Betts, A. K., Rizzo, D. M., Beckage, B., \& Bomblies, A. (2015). Characterization of increased persistence and intensity of precipitation in the northeastern United States. Geophysical Research Letters, 42(6), 1888-1893.

This Article is brought to you for free and open access by the College of Engineering and Mathematical Sciences at UVM ScholarWorks. It has been accepted for inclusion in College of Engineering and Mathematical Sciences Faculty Publications by an authorized administrator of UVM ScholarWorks. For more information, please contact scholarworks@uvm.edu. 


\section{Geophysical Research Letters}

\section{RESEARCH LETTER}

10.1002/2015GL063124

Key Points:

- Precipitation in the northeastern United States is becoming more persistent

- Precipitation in the northeastern United States is becoming more intense

- Observed trends constitute an important hydrological impact of climate change

Supporting Information:

- Figure $\mathrm{S} 1$

- Table S1

Correspondence to:

J. Guilbert,

jguilber@uvm.edu

\section{Citation:}

Guilbert, J., A. K. Betts, D. M. Rizzo, B. Beckage, and A. Bomblies (2015), Characterization of increased persistence and intensity of precipitation in the northeastern United States, Geophys. Res. Lett., 42, 1888-1893, doi:10.1002/ 2015 GL063124.

Received 14 JAN 2015 Accepted 16 FEB 2015 Accepted article online 20 FEB 2015 Published online 18 MAR 2015

\section{Characterization of increased persistence and intensity of precipitation in the northeastern United States}

\author{
Justin Guilbert ${ }^{1}$, Alan K. Betts ${ }^{2}$, Donna M. Rizzo ${ }^{1}$, Brian Beckage ${ }^{4}$, and Arne Bomblies ${ }^{1}$ \\ ${ }^{1}$ School of Engineering, University of Vermont, Burlington, Vermont, USA, ${ }^{2}$ Atmospheric Research, Pittsford, Vermont, USA, \\ ${ }^{3}$ Department of Plant Biology, University of Vermont, Burlington, Vermont, USA
}

\section{Introduction}

Concurrent with the global increase of temperature is a change in precipitation, which varies widely in magnitude and direction depending on the region considered. In general, dry areas have become drier and wet areas have become wetter [Dore, 2005]. Warming temperatures increase the potential intensity of precipitation, as saturation vapor pressure increases steeply with temperature [Durack et al., 2012; Berg et al., 2013]. Changing global circulation patterns may also have pronounced local impacts on the distribution of precipitation, influencing watershed hydrology as well as humans and natural systems. However, spatial and temporal variability in precipitation is very high, and for many regions, including the northeastern United States (NE U.S.), the connection of local-scale precipitation changes to global climate change remains elusive.

Recent research on global circulation changes suggests that arctic amplification and sea surface temperatures are drivers of changes in jet stream wave amplitude and propagation speed [e.g., Francis and Vavrus, 2012; Petoukhov et al., 2013; Screen and Simmonds, 2013; Tang et al., 2013]. One hypothesis [Francis and Vavrus, 2012] is that changing meridional temperature differences reduce jet stream intensity, resulting in higheramplitude waves and slower velocities, both of which can affect storm tracks and result in local weather impacts. However, the proposed role of arctic amplification in regulating weather patterns resulting from jet stream meanders has been criticized [Kintisch, 2014]. Other hypotheses suggest that changing sea surface temperature [Muller, 2013; Palmer, 2014] plays a similar role. Palmer [2014] proposes a mechanism that links increased sea surface temperatures (SSTs) to larger-amplitude planetary waves. In this mechanism, increased SSTs generate more powerful storms in the western tropical Pacific, and the release of latent energy excites propagating wave trains that interact with and amplify the midlatitude planetary waves. Muller [2013] suggests that warming SSTs may also contribute to the organization of squall lines in convective systems that can lead to increases in extreme precipitation.

The NE U.S. has experienced an increase in precipitation of approximately $10 \mathrm{~mm} /$ decade and the greatest increases in extreme precipitation in the United States [Horton et al., 2014]. For example, the return period of daily rainfall intensity greater than $101.6 \mathrm{~mm}(10.16 \mathrm{~cm})$ has decreased in the last century from 26 to 11 years in the NE U.S., and the frequency of the upper $10 \%$ of rainy days has increased in the NE U.S. [Groisman et al., $2001,2005]$. Under the recently proposed mechanisms that yield slower-moving planetary waves, storms are expected to propagate more slowly resulting in more persistent weather patterns. Changes in the persistence of precipitation in the NE U.S. have not been studied in detail. However, NE U.S. precipitation magnitudes show little dependence on large-scale climate variability [Brown et al., 2010; Dai, 2013]. Brown et al. [2010] considered six teleconnection patterns, while Dai [2013] looked only at the interdecadal Pacific oscillation. 
Table 1. Statistical Analysis of Regional Trends in the Probability of a Wet Day Following a Wet Day, $\mathrm{P}_{11}$

\begin{tabular}{lccccccccccccc} 
& Jan & Feb & Mar & Apr & May & Jun & Jul & Aug & Sep & Oct & Nov & Dec & Ann \\
\hline Positive trends & 139 & 146 & 156 & 157 & 179 & 178 & 159 & 160 & 168 & 166 & 157 & 150 & 168 \\
Significant positive trends & 109 & 117 & 112 & 121 & 145 & 146 & 131 & 126 & 128 & 137 & 118 & 115 & 141 \\
Negative trends & 83 & 76 & 66 & 65 & 43 & 44 & 63 & 62 & 54 & 56 & 65 & 72 & 54 \\
Significant negative trends & 57 & 50 & 50 & 39 & 32 & 28 & 44 & 43 & 42 & 39 & 46 & 55 & 36 \\
\hline
\end{tabular}

Understanding the nature of precipitation variability in the NE U.S. is critical especially with respect to severe flooding, which has become more frequent with time in this region [Collins, 2009]. In this study, we provide a statistical analysis of regional trends in the median and 95th percentile of daily precipitation and trends in wet and dry persistence. We focus on these metrics because as global temperatures continue to increase, shifts in these metrics are expected due to the dynamics of the jet stream and increasing vapor pressure of water in the atmosphere. Also, if there are continued positive trends in these metrics, we expect significant hydrologic implications including the magnitude and return intervals of severe flooding and problematic nonstationarity [Milly et al., 2008] in precipitation and river discharge.

\section{Methods}

We characterized statistical trends in regional precipitation believed to have the greatest hydrological implications: the median and 95th percentile of daily precipitation and wet and dry persistence. We used the daily data from the Global Historical Climatology Network (GHCN), retrieved from the National Climatic Data Center and covering the entire NE U.S. as defined by the National Climate Assessment. The NE U.S. as defined for this study thus includes the states of Connecticut, Delaware, Maine, Maryland, Massachusetts, New Hampshire, New York, Pennsylvania, Vermont, West Virginia, and the District of Columbia. However, no climate stations from the District of Columbia or Maryland satisfied our selection criteria. Daily precipitation from 222 stations was analyzed with record lengths varying between 51 and 174 years and a mean record length of approximately 84 years. Stations were selected such that each had over 50 years of data, and the last data point was recorded after 1 January 1990. We removed any station that was missing 10 continuous years of data; and daily precipitation values were rounded to the nearest $1 \mathrm{~mm}$. Station names and locations are included as supplemental information.

\subsection{Characterization of Changes in Precipitation Extremes}

For each station, the depths of daily precipitation were subdivided and modeled using two distributions to better represent the extreme events of the distribution, that is, to better account for rare but important events. The first distribution was best fit to all daily precipitation depth values up to the 75 th percentile, and the second distribution was fit to the remaining upper tail. The lower values were fit utilizing an exponential distribution, while the upper values were fit with a generalized Pareto distribution. Both distributions were fit using the method of maximum likelihood estimation. The two distributions were fit for moving 30 year windows by month and annually. A 30 year window was chosen because it was found to generate enough samples within the upper $25 \%$ of the distribution to minimize noise in the Pareto fitting parameters without overly smoothing the signals. For each window, the 95th percentile and median of daily precipitation were calculated from the two distributions. This was completed for each month and annually. The 95th percentile and median of daily precipitation were selected to represent heavy and average daily precipitations, respectively. A linear model was fit to determine the trends of these metrics over time. Trend magnitudes were calculated using the slope of the best fit linear model. Interquartile ranges were calculated for the trend

Table 2. Statistical Analysis of Regional Trends in the Probability of a Dry Day Following a Dry Day, $P_{00}$

\begin{tabular}{lccccccccccccc} 
& Jan & Feb & Mar & Apr & May & Jun & Jul & Aug & Sep & Oct & Nov & Dec & Ann \\
\hline Positive trends & 128 & 132 & 151 & 125 & 105 & 108 & 112 & 106 & 71 & 70 & 95 & 108 & 110 \\
Significant positive trends & 98 & 108 & 117 & 101 & 85 & 83 & 84 & 73 & 48 & 45 & 60 & 81 & 83 \\
Negative trends & 94 & 90 & 71 & 97 & 117 & 114 & 110 & 116 & 151 & 152 & 127 & 114 & 112 \\
Significant negative trends & 71 & 60 & 40 & 64 & 84 & 80 & 78 & 89 & 121 & 120 & 101 & 84 & 82 \\
\hline
\end{tabular}


Table 3. Statistical Analysis of Regional Trends in Median Daily Precipitation

\begin{tabular}{lccccccccccccc} 
& Jan & Feb & Mar & Apr & May & Jun & Jul & Aug & Sep & Oct & Nov & Dec & Ann \\
\hline Positive trends & 114 & 113 & 128 & 129 & 126 & 129 & 129 & 141 & 135 & 161 & 148 & 136 & 136 \\
Significant positive trends & 71 & 58 & 79 & 75 & 72 & 78 & 86 & 97 & 87 & 120 & 101 & 88 & 93 \\
Negative trends & 108 & 109 & 94 & 93 & 96 & 93 & 93 & 81 & 87 & 61 & 74 & 86 & 86 \\
Significant negative trends & 76 & 74 & 66 & 69 & 71 & 65 & 59 & 48 & 55 & 46 & 41 & 61 & 66 \\
\hline
\end{tabular}

magnitudes of each metric for the whole region by combining all 222 stations. Comparisons were performed between the number of positive trends and negative trends and significant $(p<0.01)$ positive and negative trends using the Mann-Kendall test (Table 1).

\subsection{Characterization of Changes in Wet and Dry Persistence}

The Markov chain parameters in this study represent the probability of transition from dry day to dry day $\left(\mathrm{P}_{00}\right)$ and the probability of transition from wet day to wet day $\left(P_{11}\right)$ (Tables 1 and 2$) . P_{00}$ is used as an analogue for dry persistence, while $P_{11}$ is used as the analogue for wet persistence. Wet days are defined as days that record $\geq 0.5 \mathrm{~mm}$ of precipitation. For each station, a moving average of $P_{00}$ and $P_{11}$ was calculated by month and annually using a 30 year window. A 30 year window was used to be consistent with the window size used to characterize the precipitation extremes. Again, the slope of a best fit linear model was used to calculate the trend magnitudes in the metrics, and comparisons were performed on the trends in $\mathrm{P}_{00}$ and $\mathrm{P}_{11}$ across the study region as described in the previous section.

\section{Results and Discussion}

The observation records show precipitation to be nonstationary in time. Of the four statistics computed, only the median daily precipitation (Table 3) remained largely unchanged. The 95th percentile of daily precipitation for the study region generally increases over the observed record (Figure 1). More than 148 (two thirds) of the 222 stations show positive trends for the 95th percentile of daily precipitation in the months of October through May, and at least half of the stations display significant $(p<0.01)$ positive trends during every month except July and September. The strongest regional trend in the 95th percentile of daily precipitation was observed in April when the average trend was $+0.7 \mathrm{~mm} / \mathrm{d} / \mathrm{decade}$. It should also be noted that the interquartile

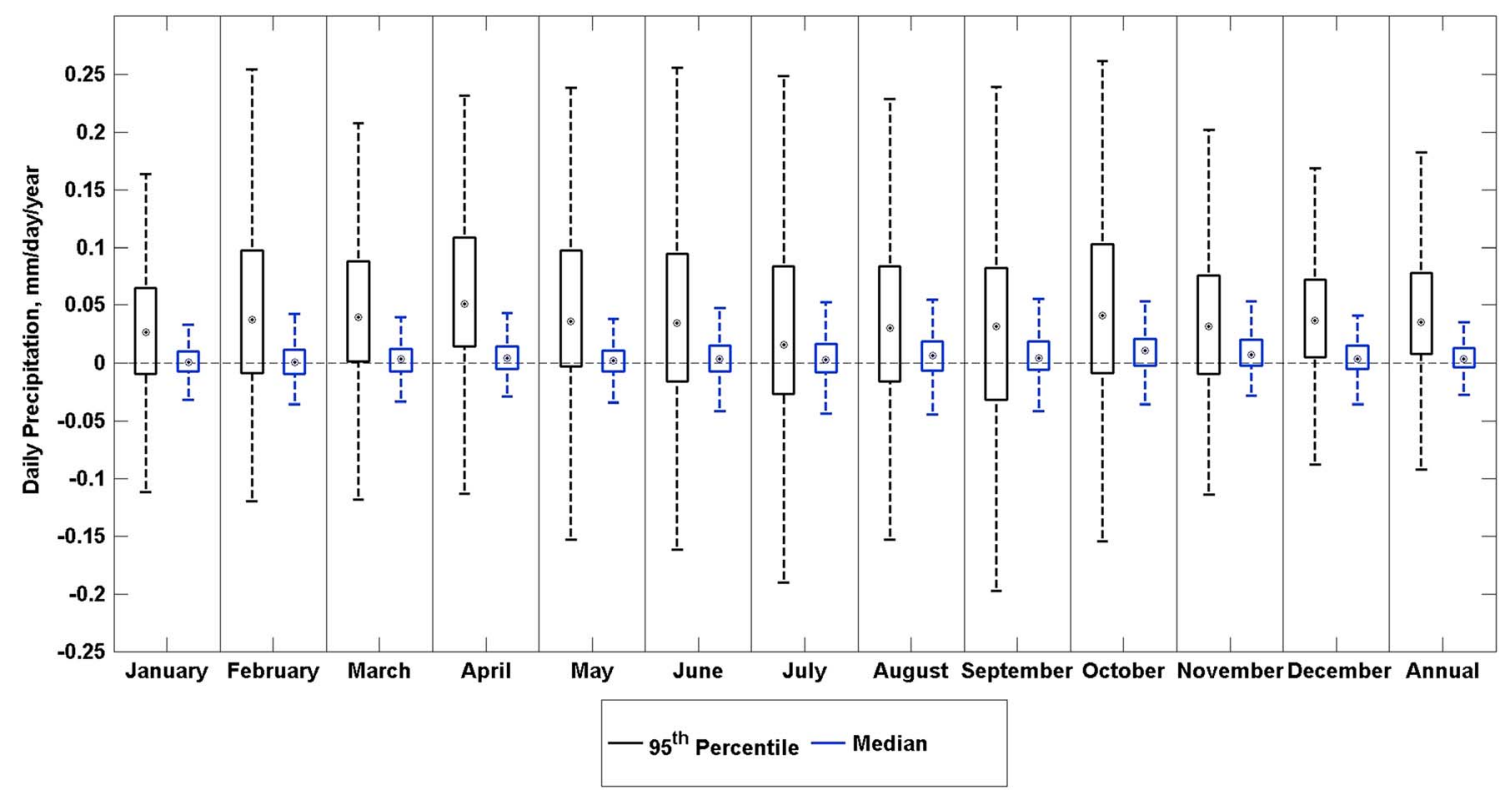

Figure 1. Regional trends in the median and 95th percentile of daily precipitation over the period of record for 222 Global Historical Climate Network stations. The dots represent the monthly or annual mean trend, the rectangle represents the interquartile range of the trend, and the whiskers represent the full range. Outliers are not shown for viewing purposes. This figure shows that the trends in the 95th percentile of daily precipitation are most significant during December, March, and April and are generally increasing at a greater rate than the median. However, there is much greater variability in the trends of the 95 th percentile. 


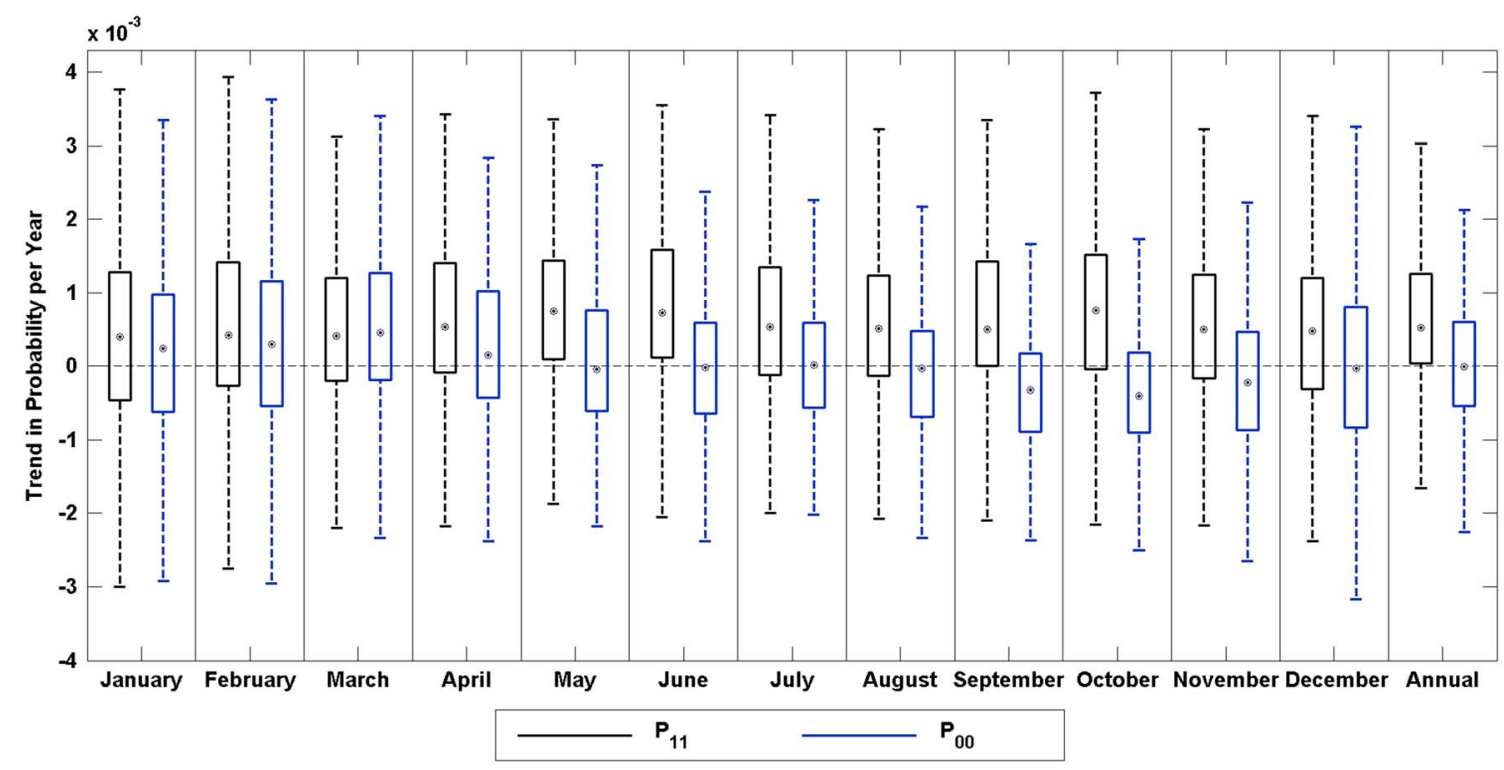

Figure 2. Regional trends in the Markov chain parameters of daily precipitation over the period of record for 222 Global Historical Climate Network stations. The dots represent the monthly or annual mean trend, the rectangle represents the interquartile range of the trend, and the whiskers represent the full range. Outliers are not shown for viewing purposes. This figure displays the trends in $\mathrm{P}_{11}$; the greatest increases in wet persistence occurred during the months of May and June, while the trends in $\mathrm{P}_{00}$ show decreasing dry persistence during September and October and increasing dry persistence in March.

range of the observed trends for the 95th percentile of daily precipitation is largest in September. The trends in the median of daily precipitation are much less pronounced with October being the only month with more than half of the stations showing significant $(p<0.01)$ positive trends; and there are no months in which more than half of the stations show significant negative trends for the median of daily precipitation. These results are representative of the 10 NE U.S. states. However, these trends are not spatially uniform. The entire region experienced an average trend of $+0.5 \mathrm{~mm} /$ decade in the annual 95th percentile daily precipitation, while Connecticut was found to have the greatest increase with a trend of $+1.1 \mathrm{~mm} / \mathrm{d} /$ decade in the annual 95th percentile daily precipitation. No trend was found for West Virginia in the annual 95th percentile daily precipitation.

Figure 2 shows the trends in both Markov chain parameters, wet persistence $\left(P_{11}\right)$, and dry persistence $\left(P_{00}\right)$. However, the trends in dry persistence are generally smaller in magnitude with some seasonal variation, small increases in spring, and small decreases in fall. For trends in dry persistence, the most positive trends (151) and significant $(p<0.01)$ positive trends (117) occur in March, the most negative trends (152) occur in October, and the highest number of significant $(p<0.01)$ negative trends $(121)$ occur in September. The wet persistence of events increases throughout the entire year with the greatest number of increasing trends occurring in May and June with 179 and 178 stations displaying positive trends, respectively, and 145 and 146 significant $(p<0.01)$ positive trends, respectively. May and June show the strongest trends with an average regional trend in the probability of a wet day following a wet day of +0.8 and $+0.9 \% /$ decade, respectively. The trends in Markov chain parameters vary spatially. Vermont and Massachusetts displayed the greatest trends in wet persistence with the annual average probability of a wet day following a wet day increasing by 0.013/decade, while Pennsylvania and Connecticut showed the smallest trend in the annual wet persistence with increases of $0.003 /$ decade.

For daily precipitation events, the warmer months show the greatest increase in wet persistence, the colder months show larger increases in the magnitude of extremes, and dry persistence increases in early spring and decreases in early fall. Annually, the interquartile ranges of the trends in both $\mathrm{P}_{11}$ and the 95th percentile of daily precipitation are above zero. Therefore, on an annual basis, it is likely that the study region will experience increasingly persistent and intense precipitation events.

Our results are largely consistent with previous work on precipitation trends in the NE U.S. Wet and dry persistence, however, have not been studied in detail for the NE U.S.. Studies of precipitation persistence have been performed in areas such as Europe where it has been observed that precipitation is trending 
Table 4. Statistical Analysis of Regional Trends in the 95th Percentile Daily Precipitation

\begin{tabular}{lccccccccccccc} 
& Jan & Feb & Mar & Apr & May & Jun & Jul & Aug & Sep & Oct & Nov & Dec & Ann \\
\hline Positive trends & 150 & 155 & 168 & 181 & 162 & 150 & 137 & 147 & 143 & 156 & 152 & 177 & 179 \\
Significant positive trends & 113 & 125 & 137 & 148 & 127 & 115 & 92 & 113 & 97 & 116 & 113 & 136 & 150 \\
Negative trends & 72 & 67 & 54 & 41 & 60 & 72 & 85 & 75 & 79 & 66 & 70 & 45 & 43 \\
Significant negative trends & 41 & 40 & 31 & 20 & 38 & 38 & 54 & 45 & 56 & 44 & 37 & 31 & 28 \\
\hline
\end{tabular}

toward longer wet spells with higher intensities [Zolina et al., 2010]. Intense precipitation has been studied in the NE U.S. [Douglas and Fairbank, 2011; Walsh et al., 2014]. The National Climate Assessment reported that in the NE U.S., more precipitation is falling annually and a higher percentage of rainfall is occurring in the upper $1 \%$ of daily events with time [Walsh et al., 2014]. Our results are consistent with increases in total annual precipitation because with increases in wet persistence and the 95th percentile of daily precipitation, and minimal trends in dry persistence and median daily precipitation, there would be more annual precipitation. Also, our results are consistent with an increased amount of precipitation occurring in the upper $1 \%$ of the events. Our results are consistent because we found that the 95th percentile of daily precipitation was increasing, which can be translated as a greater percentage of daily precipitation events falling above a stationary threshold in time.

Increases in the 95th percentile of daily precipitation (Table 4) indicate that the upper tail of the distribution of daily precipitation is increasing in magnitude, thus higher probability density in the upper percentiles of the distribution. If the probability of persistent precipitation is increasing along with the probability of observing a given high-intensity event, then the probability of an intense event following a persistent pattern is likely increasing with time, which has significant flooding implications. High-magnitude flooding can result even when long periods of time pass between a persistently wet regime and an intense precipitation event due to hysteresis within soils and watershed memory. All of this is consistent with an intensification of the water cycle and large-amplitude, slow-moving planetary waves. Another possible explanation for the observed increases in wet persistence during the spring months is that more moisture may be available earlier for evaporation as a result of earlier spring thaws. Similarly, if arctic regions that had previously stayed frozen are now thawing during summer months, this could increase moisture fluxes into the northeastern U.S. These linkages would need further study, but it is possible that long-term satellite imagery of the Northern Hemisphere could be used for this.

\section{Acknowledgments}

The data for this paper are available from the National Climatic Data Center's Global Historical Climatology Network-Daily (GHCN-Daily). This work was supported by Vermont EPSCoR through NSF award EPS-1101317.

The Editor thanks two anonymous reviewers for their assistance in evaluating this paper.

\section{References}

Berg, P., C. Moseley, and J. O. Haerter (2013), Strong increase in convective precipitation in response to higher temperatures, Nat. Geosci., doi:10.1038/ngeo1731.

Brown, P. J., R. S. Bradley, and F. T. Keimig (2010), Changes in extreme climate indices for the northeastern United States, 1870-2005, J. Clim., 23(24), 6555-6572, doi:10.1175/2010JCLI3363.1.

Collins, M. J. (2009), Evidence for changing flood risk in New England since the late 20th century, JAWRA J. Am. Water. Resour. Assoc., 45(2), 279-290, doi:10.1111/j.1752-1688.2008.00277.x.

Dai, A. (2013), The influence of the inter-decadal Pacific oscillation on U.S. precipitation during 1923-2010, Clim. Dyn., 41(3-4), 633-646, doi:10.1007/s00382-012-1446-5.

Dore, M. H. I. (2005), Climate change and changes in global precipitation patterns: What do we know?, Environ. Int., 31(8), 1167-1181, doi:10.1016/j.envint.2005.03.004.

Douglas, E., and C. Fairbank (2011), Is precipitation in northern New England becoming more extreme? Statistical analysis of extreme rainfall in Massachusetts, New Hampshire, and Maine and updated estimates of the 100 year storm, J. Hydrol. Eng., 16(3), 203-217, doi:10.1061/ (ASCE)HE.1943-5584.0000303.

Durack, P. J., S. E. Wijffels, and R. J. Matear (2012), Ocean salinities reveal strong global water cycle intensification during 1950 to 2000 , Science, 336(6080), 455-458, doi:10.1126/science.1212222.

Francis, J. A., and S. J. Vavrus (2012), Evidence linking Arctic amplification to extreme weather in mid-latitudes, Geophys. Res. Lett., 39, L06801, doi:10.1029/2012GL051000.

Groisman, P. Y., R. W. Knight, and T. R. Karl (2001), Heavy precipitation and high streamflow in the contiguous United States: Trends in the twentieth century, Bull. Am. Meteorol. Soc., 82(2), 219-246, doi:10.1175/1520-0477(2001)082<0219:HPAHSI>2.3.CO;2.

Groisman, P. Y., R. W. Knight, D. R. Easterling, T. R. Karl, G. C. Hegerl, and V. N. Razuvaev (2005), Trends in intense precipitation in the climate record, J. Clim., 18(9), 1326-1350, doi:10.1175/JCLI3339.1.

Horton, R., G. Yohe, W. Easterling, R. Kates, M. Ruth, E. Sussman, A. Whelchel, D. Wolfe, and F. Lipschultz (2014), Ch. 16: Northeast, Climate Change Impacts in the United States, The Third National Climate Assessment, edited by J. M. Melillo, T. C. Richmond, and G. W. Yohe, pp. 371-395, U.S. Global Change Research Program, Washington, D. C., doi:10.7930/J0SF2T3P.

Kintisch, E. (2014), Into the maelstrom, Science, 344(6181), 250-253, doi:10.1126/science.344.6181.250.

Milly, P. C. D., B. Julio, F. Malin, M. Robert, W. Zbigniew, P. Dennis, and J. Ronald (2008), Stationarity is dead, Ground Water News Views, 4(1), 6-8, doi:10.1126/science.1151915.

Muller, C. (2013), Impact of convective organization on the response of tropical precipitation extremes to warming, J. Clim., 26(14), 5028-5043, doi:10.1175/JCLI-D-12-00655.1. 
Palmer, T. (2014), Record-breaking winters and global climate change, Science, 344(6186), 803-804, doi:10.1126/science.1255147.

Petoukhov, V., S. Rahmstorf, S. Petri, and H. J. Schellnhuber (2013), Quasiresonant amplification of planetary waves and recent Northern Hemisphere weather extremes, Proc. Natl. Acad. Sci. U.S.A., 110(14), 5336-5341, doi:10.1073/pnas.1222000110.

Screen, J. A., and I. Simmonds (2013), Exploring links between Arctic amplification and mid-latitude weather, Geophys. Res. Lett., 40, 959-964, doi:10.1002/grl.50174.

Tang, Q., X. Zhang, and J. A. Francis (2013), Extreme summer weather in northern mid-latitudes linked to a vanishing cryosphere, Nat. Clim. Change, doi:10.1038/nclimate2065.

Walsh, J., et al. (2014), Ch. 2: Our Changing Climate, Climate Change Impacts in the United States, The Third National Climate Assessment, edited by J. M. Melillo, T. C. Richmond, and G. W. Yohe, U.S. Global Change Research Program, pp. 19-67, doi:10.7930/JOKW5CXT.

Zolina, O., C. Simmer, S. K. Gulev, and S. Kollet (2010), Changing structure of European precipitation: Longer wet periods leading to more abundant rainfalls, Geophys. Res. Lett., 37, L06704, doi:10.1029/2010GL042468. 